\title{
The 2018-19 Arctic stratospheric polar vortex
}

Article

Accepted Version

Lee, S. H. and Butler, A. H. (2020) The 2018-19 Arctic stratospheric polar vortex. Weather, 75 (2). pp. 52-57. ISSN 0043-1656 doi: https://doi.org/10.1002/wea.3643 Available at https://centaur.reading.ac.uk/87110/

It is advisable to refer to the publisher's version if you intend to cite from the work. See Guidance on citing.

To link to this article DOI: http://dx.doi.org/10.1002/wea.3643

Publisher: Wiley

All outputs in CentAUR are protected by Intellectual Property Rights law, including copyright law. Copyright and IPR is retained by the creators or other copyright holders. Terms and conditions for use of this material are defined in the End User Agreement.

\section{www.reading.ac.uk/centaur}

\section{CentAUR}

Central Archive at the University of Reading

Reading's research outputs online 
9 Keywords: stratosphere, sudden stratospheric warming, polar vortex

10 Corresponding author: Simon Lee, s.h.lee@pgr.reading.ac.uk

\section{$11 \quad$ Funding}

\section{The 2018-19 Arctic Stratospheric Polar Vortex}

\author{
Simon H. Lee ${ }^{1}$ and Amy H. Butler ${ }^{2,3}$
}

${ }^{1}$ Department of Meteorology, University of Reading, Reading, UK

Boulder, Colorado, USA

${ }^{3}$ National Oceanic and Atmospheric Administration, Earth

\section{Abstract} cold-wave.

${ }^{2}$ Cooperative Institute for Research in Environmental Sciences, University of Colorado

System Research Laboratory, Chemical Sciences Division, Boulder, Colorado, USA

S. H. L. was funded by the Natural Environment Research Council (NERC) via the SCENARIO doctoral training partnership at the University of Reading (NE/L002566/1).

The stratospheric polar vortex is a westerly circulation that forms over the winter pole around $10-50 \mathrm{~km}$ above the surface, which is known to influence mid-latitude weather patterns. During 2018-19, the Arctic polar vortex demonstrated an unusually large amount of variability, including a strong and persistent sudden stratospheric warming (SSW) event, a strong vortex event, and a dynamic final stratospheric warming (FSW). In this article we discuss the evolution of the vortex, placing it in the context of wider observed climatology, and comment on its apparent impacts on tropospheric weather patterns - notably, the lack of a surface climate response to the SSW of similar magnitude to the February-March 2018 "Beast from the East" 


\section{Introduction}

The stratospheric polar vortex (SPV) is a planetary-scale cyclonic circulation which forms over the winter pole each year in the stratosphere (the layer of the atmosphere $10-50 \mathrm{~km}$ above the surface) and is encircled by the westerly polar night jet stream. The vortex develops due to seasonal radiative cooling owing to the Earth's axial tilt; air within the vortex becomes isolated and can cool to below $-80^{\circ} \mathrm{C}$ as a result of the lack of solar heating. In the Northern Hemisphere $(\mathrm{NH})$, the SPV is highly variable on both intra- and inter-annual timescales. The distribution of the oceans, continents, and mountain ranges produces large-scale planetary waves in the mid-latitude tropospheric polar jet stream. Planetary-scale waves can also be formed by anomalous heating associated with tropical convection, such as the Madden-Julian Oscillation (MJO) or the El Niño-Southern Oscillation (ENSO). These waves can propagate vertically into the westerly winds of the SPV and break in the stratosphere (akin to waves breaking on a beach), depositing their momentum there and decelerating the westerly flow. Such waves can only propagate into regions of westerly flow; this communication of wave activity from the troposphere to the stratosphere is absent in the summertime when stratospheric easterlies are present. The stratospheric circulation typically only supports large-scale waves of wavenumber 1 or 2 (whereas many higher wavenumbers are present in the troposphere). Contrastingly, the Southern Hemisphere (SH) SPV is relatively strong and stable with less inter-annual variability due to the symmetric Southern Ocean encircling Antarctica.

Sometimes, the SPV can break down entirely in an event known as a sudden stratospheric warming (SSW) (Scherhag, 1952). If the event is sufficiently strong to reverse the zonal-mean zonal (westerly) wind at $10 \mathrm{hPa}$ and $60^{\circ} \mathrm{N}$ (hereafter, U1060), the event is defined as major (Charlton and Polvani, 2007; Butler et al., 2015). Major SSWs occur approximately 6 times 
Nash, 2005). SSWs, as the name suggests, involve a sudden warming of the polar stratosphere

- temperatures have been observed to rise over $50^{\circ} \mathrm{C}$ in only a few days. The westerly circulation of the SPV is disrupted; the vortex either splits into two or is displaced from the pole (so-called 'split' and 'displacement' events, respectively).

The variability of the NH SPV, including SSWs and their strong-vortex counterpart, is important for day-to-day weather as it can affect the state of the tropospheric Northern Annular Mode (NAM)/Arctic Oscillation (AO), and the North Atlantic Oscillation (NAO) (Baldwin and Dunkerton, 2001; Kidston et al., 2015) - which are essentially measures of the strength of the westerly mid-latitude flow in the $\mathrm{NH}$ and North Atlantic respectively. The AO and the NAO are associated with extratropical temperature and precipitation patterns. In general, weak (strong) vortex events are followed by negative (positive) phases of the AO/NAO and colder and drier (warmer and wetter) weather in places such as Britain and northwest Europe. However, recent work has shown that the relationship between SSWs and the AO/NAO varies on a case-by-case basis, and is only a strong relationship (if at all) in approximately half of observed major SSWs (Karpechko et al., 2017). The exact reasons why some stratospheric events couple to the surface weather and some do not is poorly understood, and an area of active research. In February 2018, the first major SSW since January 2013 occurred, and the following period into March was unusually cold across Eurasia with a strongly negative NAO/AO pattern (Karpechko et al., 2018). The moniker "The Beast from the East" was widely used to describe the easterly flow which brought record-breaking cold temperatures to northwest Europe, including the UK (Greening and Hodgson, 2019). In contrast, the SSW in January 2019 was not followed by similarly cold conditions in Europe. 
74 In this article, we discuss the evolution of the Arctic SPV during 2018-19. The SPV exhibited an unusually high level of variability during this winter, including a major SSW, a strong vortex event, and a dynamically-driven final stratospheric warming. We place these events in the wider context of the observed climatology of the vortex, and comment on the impact on tropospheric weather patterns.

\section{Data}

We use data from the European Centre for Medium-Range Weather Forecasts (ECMWF) Interim reanalysis (ERA-Interim) (Dee et al., 2011), retrieved from the ECMWF MARS archive (via https://apps.ecmwf.int/datasets/). Climatological values are those observed between January 1979 and June 2018 inclusive. NAO and AO data indices are accessed from the National Centers for Environmental Prediction Climate Prediction Center (NCEP CPC) website (https://www.cpc.ncep.noaa.gov/).

\section{The Polar Vortex in 2018-19}

The evolution of the SPV during 2018-19 can be readily sorted into five distinct phases:

1) The spin-up and development of the SPV during August-October 2018.

2) Pre-SSW evolution (so-called 'pre-conditioning') of the SPV during NovemberDecember 2018.

3) The onset and evolution of the major SSW during January 2019.

4) The subsequent recovery and development of a strong SPV event during March 2019.

5) The final stratospheric warming and vortex dissipation during April 2019.

Timeseries of the evolution of $\mathrm{U}_{10} 0_{60}$ and $45-75^{\circ} \mathrm{N}$ mean eddy heat flux (denoted [ $\left.\mathrm{v}^{*} \mathrm{~T}^{*}\right]$ ) at $100 \mathrm{hPa}$ are shown in Figure 1 and Figure 2. The latter quantity is commonly used as a diagnostic of vertically propagating wave activity in the lower stratosphere. It is computed by 
calculating the area-weighted average across $45-75^{\circ} \mathrm{N}$ of the zonal-average of the products of

100 the departures from the zonal-mean $\mathrm{T}$ and $\mathrm{v}$.

101 First, we describe the stratospheric evolution during 2018-19, and then discuss the impacts on

102 the troposphere.

103

104 September-October 2018: Vortex spin-up

105 Daily mean U10 60 first became westerly on 22 August (see Figure 1), indicating the

106 development of the SPV for the 2018-19 season. This was 3 days earlier than the climatological

107 mean date of 25 August - however, variability at this time of year is small, and in all cases in

108 ERA-Interim climatology, the SPV spins up by 30 August. Zonal-mean zonal winds tracked

109 slightly below normal during September, before strengthening towards date-record strong

110 values by the second half of October 2018. Though some fluctuations occurred, U10 60 remained

111 mostly stronger than average through November.

112

\section{November-December 2018: Preconditioning}

114 During November 2018, vertically propagating wave activity began to increase. By the beginning of December, the effect of this wave activity was evident in a deceleration of U10 60 to below-normal values. Notably, the beginning of the weakened SPV occurred during the

117 period of climatological maximum wind speed, although this is also when observed variance

118 markedly increases. In early December, the amplitude of wavenumber-1 increased to above-

119 average values (i.e., a strengthened Aleutian high), and the SPV was displaced towards Eurasia

120 and became elongated (Figure 3). This is consistent with the structure and positioning of the

121 SPV prior to major SSWs. Anomalously high heat flux persisted, reaching daily $90^{\text {th }}$ percentiles

122 in the second half of the month, as shown in Figure 2. Individual daily or seasonal heat flux

123 records were not broken at $100 \mathrm{hPa}$; this pre-SSW evolution was not an example of one large 
wave pulse, but prolonged elevated wave activity. Polar cap temperatures subsequently warmed, and westerly zonal winds began to rapidly decrease during the final week of

126 December. At the same time, polar cap total column ozone increased (not shown). Stratospheric

127 ozone levels and polar vortex variability are strongly coupled - the regularity of NH SSWs and

128 the weaker SPV compared with its SH counterpart are key reasons why the Arctic does not

129 regularly see a large ozone hole. Increasing polar cap ozone is a common occurrence during

130 stratospheric vortex disruption; it is driven primarily by enhanced poleward transport from

131 equatorial regions (owing to the amplified stratospheric wave field and mixing from wave

132 breaking) where concentrations are higher (de la Cámara et al., 2018).

\section{January 2019: Major SSW}

135 Following the period of vortex weakening, daily-mean U10 60 became easterly on 2 January,

136 indicating a major SSW was underway. This was the $6^{\text {th }}$ earliest date (out of 26 events) for a 137 major SSW since 1979 (the earliest being 4 December 1981) according to ERA-Interim 138 reanalysis. The vortex was displaced towards the Atlantic sector by the strong Aleutian 139 anticyclone, and then split into two smaller vortices (Figure 4). Unlike the SSW in February 1402018 , where an unusually strong vortex was abruptly torn in two by an amplified wavenumber-

1412 pattern (i.e., both Atlantic and Aleutian ridges), the January 2019 major SSW resulted from

142 the splitting of a weak vortex by a wavenumber-1 pattern without wavenumber-2 amplification.

143 This is consistent with the prolonged elevated heat flux weakening the vortex over a longer 144 period, rather than a single extreme pulse.

146 The easterly zonal-mean zonal winds persisted for 21 days until 23 January (slightly longer 147 than the February 2018 event, and tied with February 1999 for $7^{\text {th }}$ longest in 26 events in ERA148 Interim, see Table 1), with $\mathrm{U} 10_{60}$ reaching a minimum of $-10.2 \mathrm{~m} \mathrm{~s}^{-1}$ on 10 January $\left(16^{\text {th }}\right.$ most 
149 easterly). The duration was above the mean of 14 days, but lies within 1 standard deviation (10

150 days), whilst the minimum $\mathrm{U} 10_{60}$ was slightly above the mean of $-12.1 \mathrm{~m} \mathrm{~s}^{-1}$, though also within

1511 standard deviation $\left(7.9 \mathrm{~m} \mathrm{~s}^{-1}\right)$, as shown in Figure 5. Considering all events in ERA-Interim,

152 the minimum $\mathrm{U}_{10} 0_{60}$ and the duration of the easterlies are inversely correlated (Pearson's $r=$ -

153 0.62, Spearman's ranked correlation $r=-0.69, p<0.001)$, indicating SSWs which more

154 strongly disrupt the stratospheric circulation and generate stronger easterly zonal-mean

155 momentum tend to take longer to recover to westerlies. The main exception to this is the SSW

156 of 24 February 1984, which was the longest lived (39 easterly days) but had a below-average

157 minimum wind.

158

159 Following the split of the SPV, the two smaller vortices resided over Eurasia and North

160 America. The North American lobe was associated with a surface circulation that lead to

161 record-breaking cold temperatures in the northern U.S. and Canada during late January 2019

162 (BBC News, 2019).

163

164 February-March 2019: Strong Vortex Event

165 Following the recovery of the SPV, a strong vortex event ensued on 5 March, which is defined

166 as $\mathrm{U}_{10} 0$ exceeding $41.2 \mathrm{~m} \mathrm{~s}^{-1}$, following Tripathi et al. (2015). This peaked on 12 March

167 (Figure 6), when daily-mean $\mathrm{U}_{10}$ reached $52.2 \mathrm{~m} \mathrm{~s}^{-1}$ which set new daily records (c.f. Figure

168 1) with the SPV forming an almost perfect annulus around the Arctic. The strong recovery of

169 the SPV following the SSW is dynamically consistent with the prolonged period of easterly

170 winds - these effectively 'shield' the mid-to-upper stratosphere from tropospheric planetary

171 wave activity which can only propagate into westerly flow, allowing the vortex to be

172 undisturbed and re-develop through radiative cooling. A secondary component pertains to the

173 timing of the SSW - being relatively early-season, minimal solar radiation reached the Arctic 
during the following weeks, allowing further enhanced radiative cooling. For example, a similar SSW-to-strong vortex transition was seen following the early-season SSW of 8 December 1987 (U1060 reached a date-record $70.4 \mathrm{~m} \mathrm{~s}^{-1}$ on 13 February 1988). Associated with the strong SPV were date-record-cold $10 \mathrm{hPa} 60-90^{\circ} \mathrm{N}$ average temperatures from 16 February to 19 March, with a minimum of $-75^{\circ} \mathrm{C}$ on 24 February.

\section{April 2019: Final Stratospheric Warming}

$181 \mathrm{U} 10_{60}$ became easterly again on 23 April in the final stratospheric warming (FSW), which is

182 defined to be the first day of easterly $\mathrm{U}_{10} 0_{60}$ that is not followed by a recovery to westerlies for 183 at least 10 consecutive days until the following winter season (following Butler and Gerber, 184 2018). The 2019 date is 8 days later than the climatological mean date of 15 April, which is typical of seasons with a mid-winter SSW owing to the following recovery $(\mathrm{Hu}, \mathrm{Ren}$ and $\mathrm{Xu}$, 2014). FSWs are radiatively driven as the sun returns to the Arctic pole, but can also be driven by dynamic wave forcing akin to a major SSW. The FSW in April 2019 had a substantial dynamic component, with high wave activity preceding the event (Figure 2). This developed an unusually intense Aleutian high which displaced the weakening SPV (Figure 7) and produced date-record strong easterly $\mathrm{U}_{10}$ in early May (a minimum of $-20.4 \mathrm{~m} \mathrm{~s}^{-1}$ was reached on 4 May). Although the envelope of variability becomes smaller into the summer, U10 60 remained close to date-record minima through June.

\section{Connection to the Troposphere}

195 The dynamic connection between the stratosphere and troposphere can be readily shown by a vertical cross-section of a timeseries of polar cap geopotential height anomalies. These are

197 often referred to as "dripping paint" plots, as they show the downward propagation of 198 stratospheric anomalies over time. The evolution in 2018-19 is shown in Figure 8. Prior to the 
199 SSW, there is little indication of coupling between the troposphere and stratosphere, though

200 from September to November there are anomalously high geopotential heights in the

201 troposphere. This indicates a tendency toward blocked and amplified mid-latitude flow, which

202 may have helped drive the high wave activity during autumn 2018. Following the SSW, the

203 associated anomalies did not propagate downwards below $\sim 200 \mathrm{hPa}$ into the troposphere until

204 a brief, weak spell in early February, indicating the SSW did not couple persistently to surface weather patterns. However, it should also be noted that anomalously low geopotential heights were also absent from the Arctic troposphere during this time. Afterwards, the strong vortex event coupled strongly to the troposphere during March, and the final warming in late April also produced a very strong response at the surface that persisted through May (even though the middle-stratospheric anomalies were not as strong as during the SSW, suggesting the importance of lower-stratospheric anomalies in stratosphere-troposphere coupling).

212 The response of the troposphere to SPV variability is traditionally discerned in terms of the

213 behaviour of the hemispheric AO pattern, and the more regionalised NAO pattern. The sign of 214 these, on average, is negative following major SSWs and positive following strong SPV events.

215 For example, following the February 2018 SSW, a strong and persistent negative AO/NAO

216 pattern developed, indicating anomalously weak tropospheric westerlies. For deep and 217 persistent cold in Europe, a negative NAO is usually required. The evolution of the two indices 218 in 2018-19 is shown in Figure 9. Neither index transitioned into a strongly negative state 219 following the SSW. However, during January 2019, the AO was persistently more negative than the NAO. This indicates that whilst anomalously high pressure developed over higher

221 latitudes, this did not project onto the NAO pattern. The opposite followed during February 222 into early March, when the strongly positive AO was not reflected in a strongly positive NAO; 223 however, it is unlikely that during this time the $\mathrm{AO}$ was responding to the strong vortex at 10 
$224 \mathrm{hPa}$, as lower stratospheric winds remained weak (c.f. positive height anomalies during this time in Figure 8), possibly indicating other tropospheric drivers. During both periods, the NAO index during February was unusual in the historical record; no other February since 1950 exhibited the combination of both a weakly positive mean state and weak variance about the monthly mean. Following mid-March, the AO and NAO began to be more in-phase as the strong vortex event propagated downwards, and evolved similarly through April into May. A negative NAO/AO pattern then developed following the final warming. The NAO was more negative following the final warming than following the SSW or at any other point in the extended winter period (the mean NAO index for May 2019 was $-2.62 \sigma$, the lowest for the month of May in the CPC record stretching back to 1950) giving an unusual example of lateseason stratosphere-troposphere coupling. May 2019 was also the first month for the UK with a mean temperature below the 1981-2010 average since September 2018, and had the largest negative anomaly of any month since March 2018 (Met Office, 2019) (during which the "Beast from the East" cold-wave occurred).

\section{Conclusions}

241 During 2018-19, the stratospheric polar vortex (SPV) was highly variable, with a major split-

242 type sudden stratospheric warming (SSW) in January, followed by a strong vortex event in

243 March, culminating in a dynamic final stratospheric warming (FSW) in April. The major SSW

244 did not strongly couple with tropospheric weather patterns. The North Atlantic Oscillation

245 (NAO), which typically responds to stratospheric events, did not transition to a strong negative

246 phase following the event like in February 2018, which resulted in less notable impacts to

247 Europe in particular. In contrast, the strong vortex event did couple to the surface and generate

248 a strongly positive Arctic Oscillation (AO) and NAO in during March. Following the later than 
average dynamically driven FSW in April, the AO and NAO transitioned into strongly negative states.

\section{Acknowledgments}

S. H. L. acknowledges funding by the Natural Environment Research Council (NERC) via the

SCENARIO doctoral training partnership at the University of Reading (NE/L002566/1).

\section{References}

Baldwin, M. P. and Dunkerton, T. J. (2001) 'Stratospheric Harbingers of Anomalous Weather

Regimes', Science, 294(5542), pp. 581-584.

BBC News (2019) Polar vortex death toll rises to 21 as US cold snap continues. Available at: https://www.bbc.com/news/world-us-canada-47088684 (Accessed: 10 May 2019).

Butler, A. H. et al. (2015) 'Defining sudden stratospheric warmings', Bulletin of the American

Butler, A. H. et al. (2017) 'A sudden stratospheric warming compendium', Earth System Science Data, 9(1), pp. 63-76. doi: 10.5194/essd-9-63-2017.

Butler, A. H. and Gerber, E. P. (2018) 'Optimizing the definition of a sudden stratospheric warming', Journal of Climate, 31(6), pp. 2337-2344. doi: 10.1175/JCLI-D-17-0648.1.

Charlton, A. J. and Polvani, L. M. (2007) 'A new look at stratospheric sudden warmings. Part

268 I: Climatology and modelling benchmarks', Journal of Climate, 20(3), pp. 449-469. doi:

\section{$269 \quad 10.1175 / J C L I 3996.1$.}

270 Dee, D. P. et al. (2011) 'The ERA-Interim reanalysis: Configuration and performance of the

271 data assimilation system', Quarterly Journal of the Royal Meteorological Society, 137(656), 272 pp. 553-597. doi: 10.1002/qj.828.

273 Greening, K. and Hodgson, A. (2019) 'Atmospheric analysis of the cold late February and early 
274 March 2018 over the UK', Weather, 74(3), pp. 79-85. doi: 10.1002/wea.3467.

$275 \mathrm{Hu}$, J., Ren, R. and Xu, H. (2014) 'Occurrence of Winter Stratospheric Sudden Warming

276 Events and the Seasonal Timing of Spring Stratospheric Final Warming, Journal of the 277 Atmospheric Sciences, 71(7), pp. 2319-2334. doi: 10.1175/jas-d-13-0349.1.

278 Karpechko, A. Y. et al. (2017) 'Predictability of downward propagation of major sudden 279 stratospheric warmings', Quarterly Journal of the Royal Meteorological Society. Wiley280 Blackwell, 143(704), pp. 1459-1470. doi: 10.1002/qj.3017.

281 Karpechko, A. Y. et al. (2018) 'Predicting Sudden Stratospheric Warming 2018 and Its Climate 282 Impacts With a Multimodel Ensemble', Geophysical Research Letters, 45(24), p. 13,538283 13,546. doi: 10.1029/2018GL081091.

284 Kidston, J. et al. (2015) 'Stratospheric influence on tropospheric jet streams, storm tracks and 285 surface weather', Nature Geoscience. Nature Publishing Group, 8(6), pp. 433-440. doi: 286 10.1038/NGEO2424. de la Cámara, A. et al. (2018) 'Response of Arctic ozone to sudden stratospheric warmings', Atmospheric Chemistry and Physics, 18(22), pp. 16499-16513. doi: 10.5194/acp-18-164992892018.

Met Office (2019) UK climate maps and data. Available at:

291 https://www.metoffice.gov.uk/research/climate/maps-and-data (Accessed: 1 July 2019).

292 Newman, P. A. and Nash, E. R. (2005) 'The Unusual Southern Hemisphere Stratosphere 293 Winter of 2002', Journal of the Atmospheric Sciences, 62(3), pp. 614-628. doi: 10.1175/JAS2943323.1.

295 Scherhag, R. (1952) 'Die explosionsartigen Stratospherenerwarmingen des Spatwinters', Ber. 296 Dtsch. Wetterdienstes U.S. Zone, 38, pp. 51-63.

297 Tripathi, O. P. et al. (2015) 'Enhanced long-range forecast skill in boreal winter following 298 stratospheric strong vortex conditions', Environmental Research Letters. IOP Publishing, 

10(10), p. 104007. doi: 10.1088/1748-9326/10/10/104007.

300 
Figure 1: Evolution of $10 \mathrm{hPa} 60^{\circ} \mathrm{N}$ zonal-mean zonal winds from July 2018 through June 2019 according to ERA-Interim reanalysis. Climatological values are also indicated.

304 Figure 2: Timeseries of meridional eddy heat flux at $100 \mathrm{hPa}$, averaged across $45-75^{\circ} \mathrm{N}$, from July 2018 through June 2019, according to ERA-Interim reanalysis. Climatological values are also indicated.

Figure 3: $10 \mathrm{hPa}$ wind (filled) and geopotential height (contoured) for 00Z 12 December 2018 according to ERA-Interim reanalysis. Also indicated are the $60^{\circ} \mathrm{N}$ zonal-mean zonal-wind ([U] $\left.60^{\circ} \mathrm{N}\right)$ and the minimum and maximum geopotential height in the domain $\left(\mathrm{Z}_{\min }\right.$ and $\left.\mathrm{Z}_{\max }\right)$.

312 Figure 4: As in Figure 3 but for 2 January 2019 at the onset of the major SSW.

314 Figure 5: (a) Persistence of each SSW as defined by cumulative easterly zonal-mean zonal 315 wind days at $10 \mathrm{hPa} 60^{\circ} \mathrm{N}$, (b) minimum $10 \mathrm{hPa} 60^{\circ} \mathrm{N}$ zonal-mean zonal wind during each 316 SSW, and (c) a scatter plot of duration versus minimum zonal-mean zonal wind, for all major 317 SSWs in ERA-Interim reanalysis 1979-2019. Red (blue) indicates the SSW is classified as 318 (non-)downward propagating in Karpechko et al. (2017), extended to include the 2018 and 2019 events. The SSW of 24 March 2010, shown in grey, was not classified in that study. In (a) and (b) the black dashed (dotted) lines denote the mean (standard deviations) of each quantity. In (c) the linear regression is shown with a solid black line.

Figure 6: As in Figure 3 but for 12 March 2019 at the peak of the strong vortex event.

325 Figure 7: As in Figure 3 but for 23 April at the onset of the final warming. 
326 Figure 8: Timeseries of $60-90^{\circ} \mathrm{N}$ average geopotential height anomalies from 1 August 2018

327 through 31 May 2019 in ERA-Interim. Anomalies are standardized departures expressed with

328 respect to the daily mean and standard deviation from 1979-2019. Vertical dashed lines indicate

329 (from left-to-right) the vortex spin-up, the major SSW, the peak of the strong vortex event, and

330 the final warming.

331

332 Figure 9: Timeseries of daily North Atlantic Oscillation (NAO, left-hand axis in blue) and

333 Arctic Oscillation (AO, right-hand axis in red) for 1 November 2018 to 31 May 2019. 
334 Table 1: Top 10 (of 26) major SSWs in ERA-Interim ranked by persistence of easterlies. 2019

335 is indicated in bold. The duration is defined following Charlton and Polvani (2007) - these are

336 the total number of easterly days associated with the event and are not necessarily consecutive.

\begin{tabular}{|l|l|l|}
\hline Rank & Major SSW & Persistence (days) \\
\hline 1 & 24 Feb 1984 & 39 \\
\hline 2 & 24 Jan 2009 & 30 \\
\hline 3 & 23 Jan 1987 & 29 \\
\hline 4 & 21 Feb 1989 & 28 \\
\hline 5 & 21 Jan 2006 & 26 \\
\hline 6 & 6 Jan 2013 & 22 \\
\hline 7 (tied) & 2 Jan 2019 & $\mathbf{2 1}$ \\
\cline { 2 - 4 } & 26 Feb 1999 & 21 \\
\hline 9 & 12 Feb 2018 & 19 \\
\hline 10 & 22 Feb 2008 & 15 \\
\hline
\end{tabular}




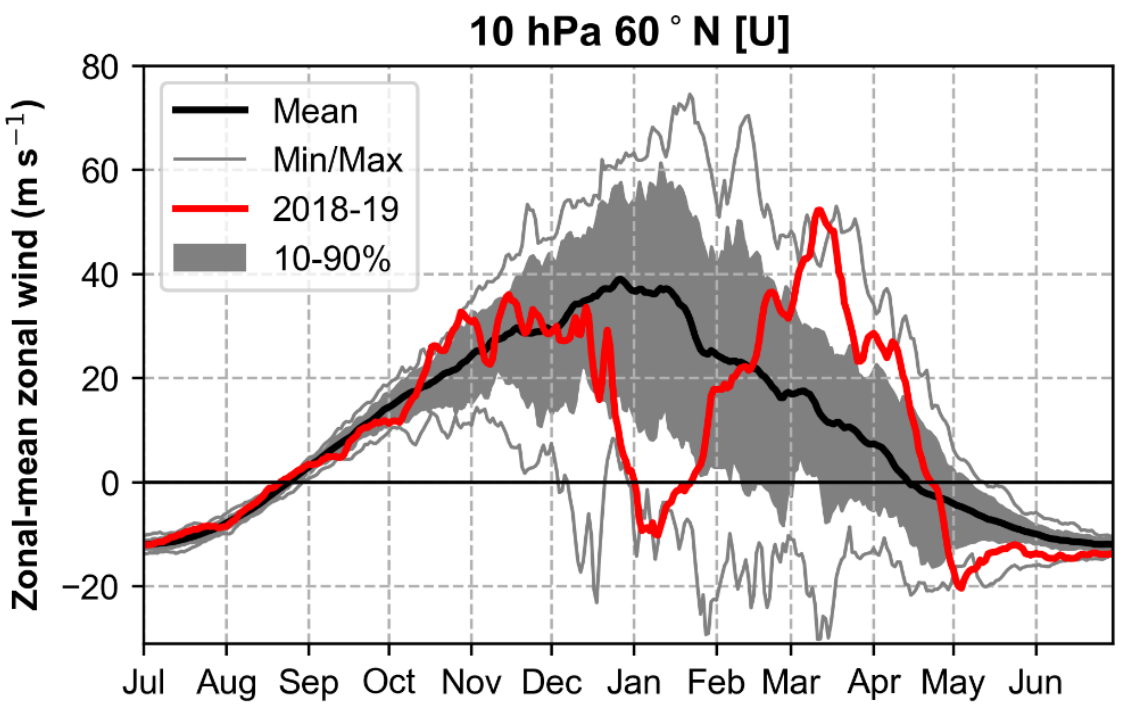

Figure 1: Evolution of $10 \mathrm{hPa} 60^{\circ} \mathrm{N}$ zonal-mean zonal winds from July 2018 through June 2019

341 according to ERA-Interim reanalysis. Climatological values are also indicated.

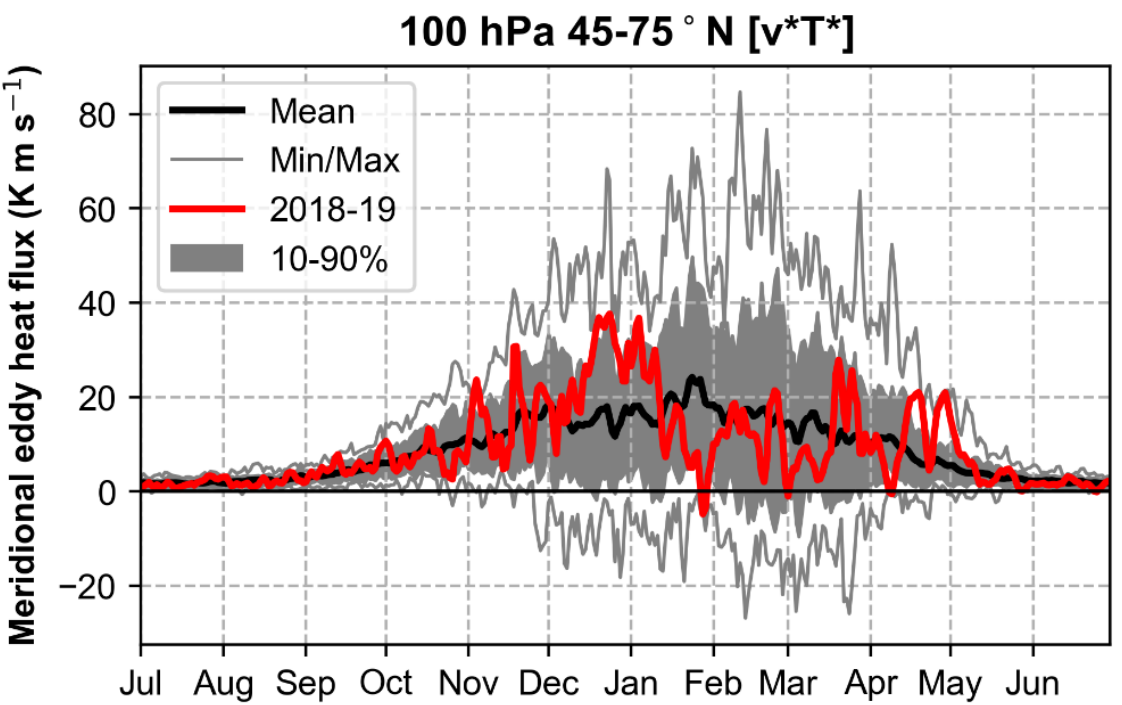

342

Figure 2: Timeseries of meridional eddy heat flux at $100 \mathrm{hPa}$, averaged across $45-75^{\circ} \mathrm{N}$, from

344 July 2018 through June 2019, according to ERA-Interim reanalysis. Climatological values are 345 also indicated. 


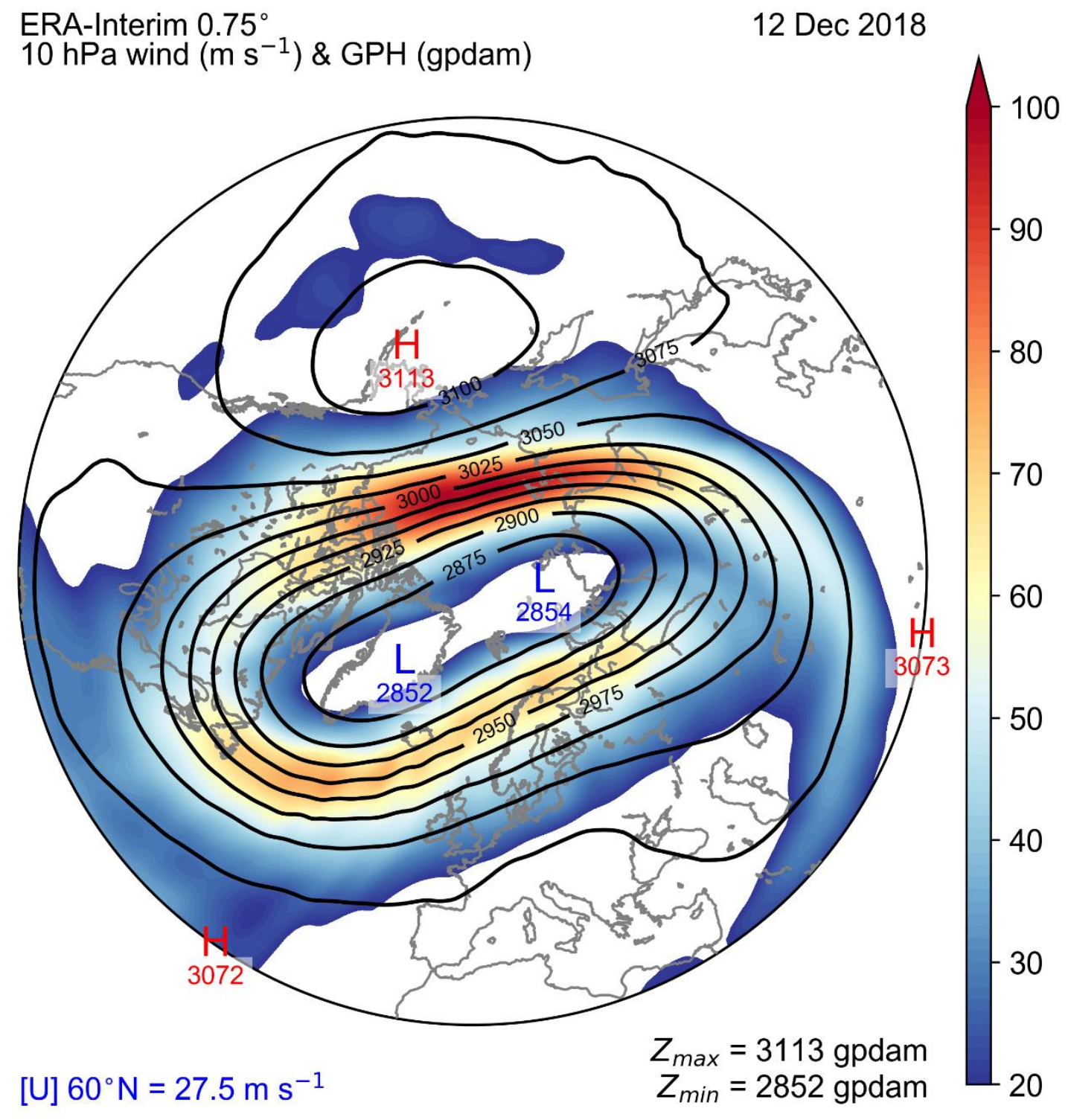

347 Figure 3: $10 \mathrm{hPa}$ wind (filled) and geopotential height (contoured) for 00Z 12 December 2018

348 according to ERA-Interim reanalysis. Also indicated are the $60^{\circ} \mathrm{N}$ zonal-mean zonal-wind ([U] $60^{\circ} \mathrm{N}$ ) and the minimum and maximum geopotential height in the domain (Zmin and Zmax). 


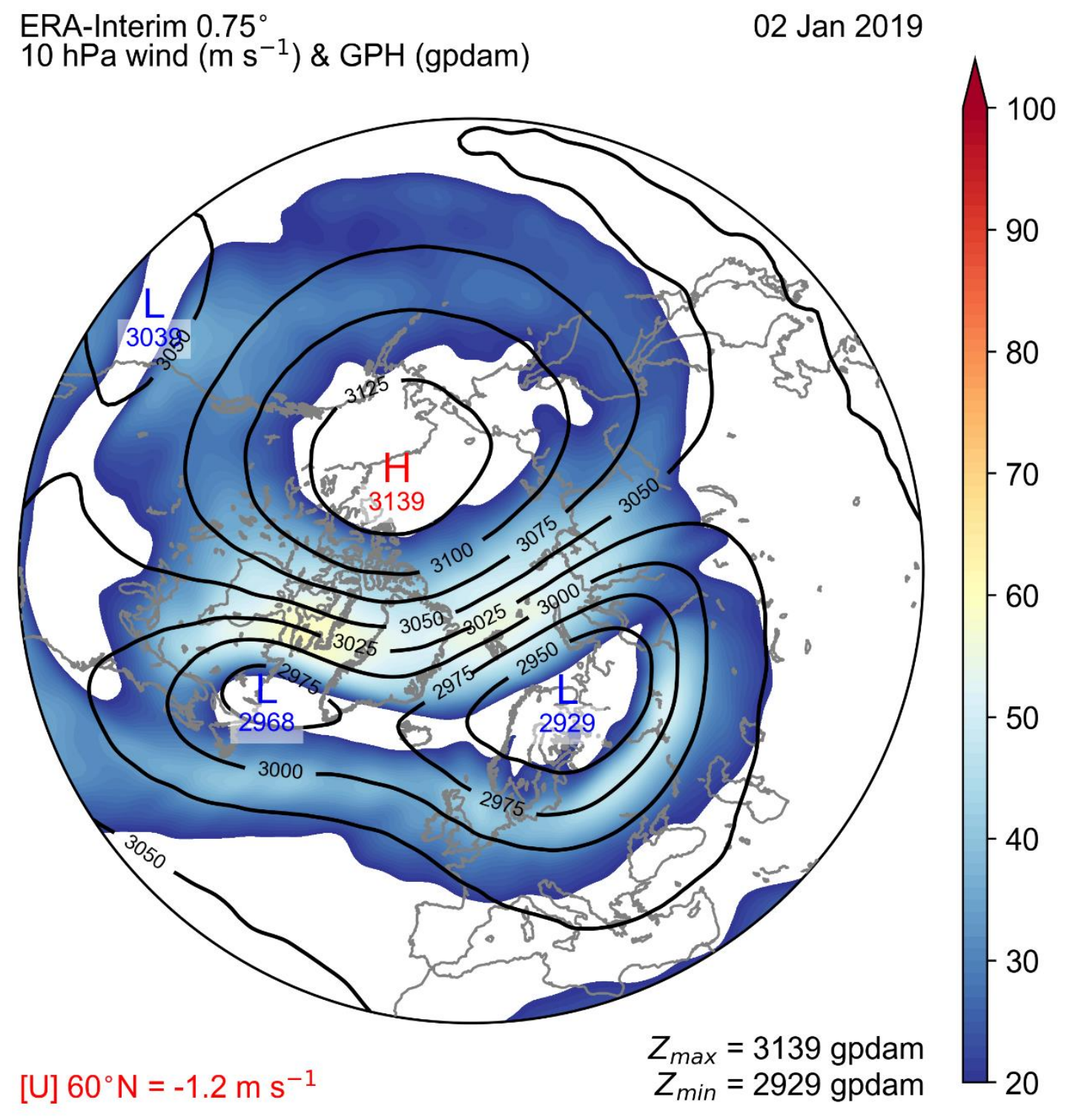

Figure 4: As in Figure 3 but for 2 January 2019 at the onset of the major SSW. 

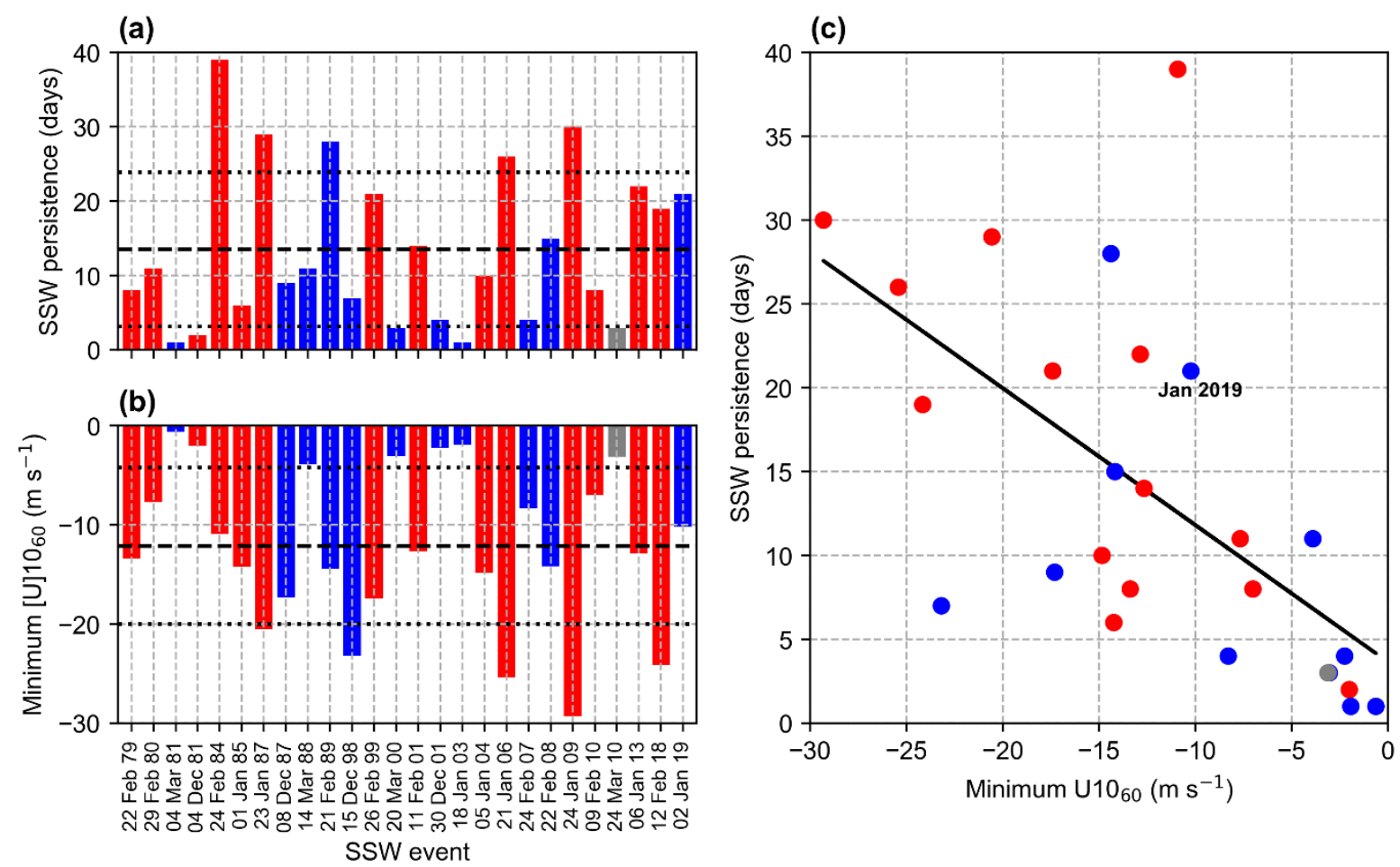

353 Figure 5: (a) Persistence of each SSW as defined by cumulative easterly zonal-mean zonal wind days at $10 \mathrm{hPa} 60^{\circ} \mathrm{N}$, (b) minimum $10 \mathrm{hPa} 60^{\circ} \mathrm{N}$ zonal-mean zonal wind during each SSW, and (c) a scatter plot of duration versus minimum zonal-mean zonal wind, for all major SSWs in ERA-Interim reanalysis 1979-2019. Red (blue) indicates the SSW is classified as

357 (non-)downward propagating in Karpechko et al. (2017), extended to include the 2018 and 2019 events. The SSW of 24 March 2010, shown in grey, was not classified in that study. In (a) and (b) the black dashed (dotted) lines denote the mean (standard deviations) of each quantity. In (c) the linear regression is shown with a solid black line. 


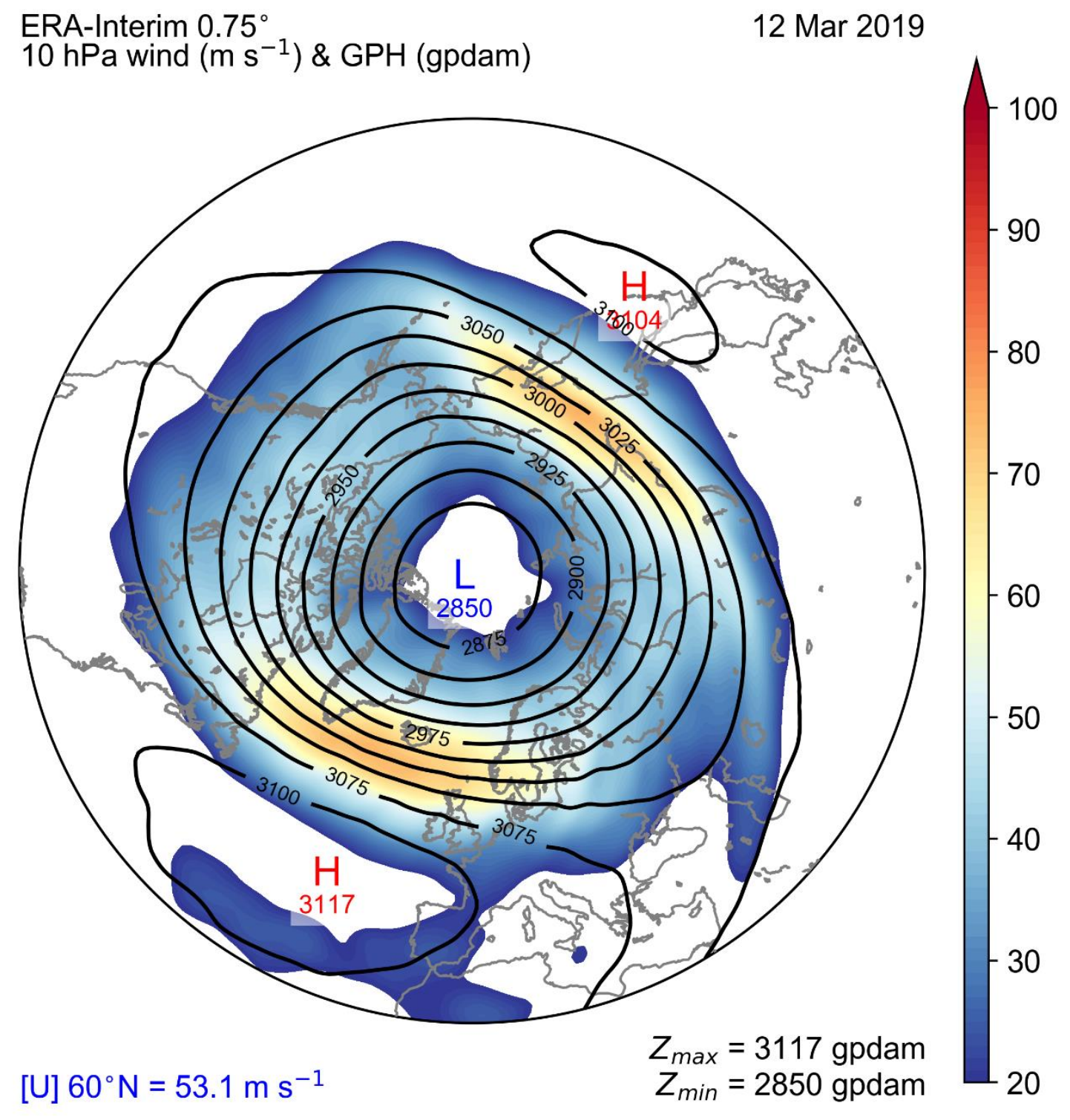

362 Figure 6: As in Figure 3 but for 12 March 2019 at the peak of the strong vortex event. 


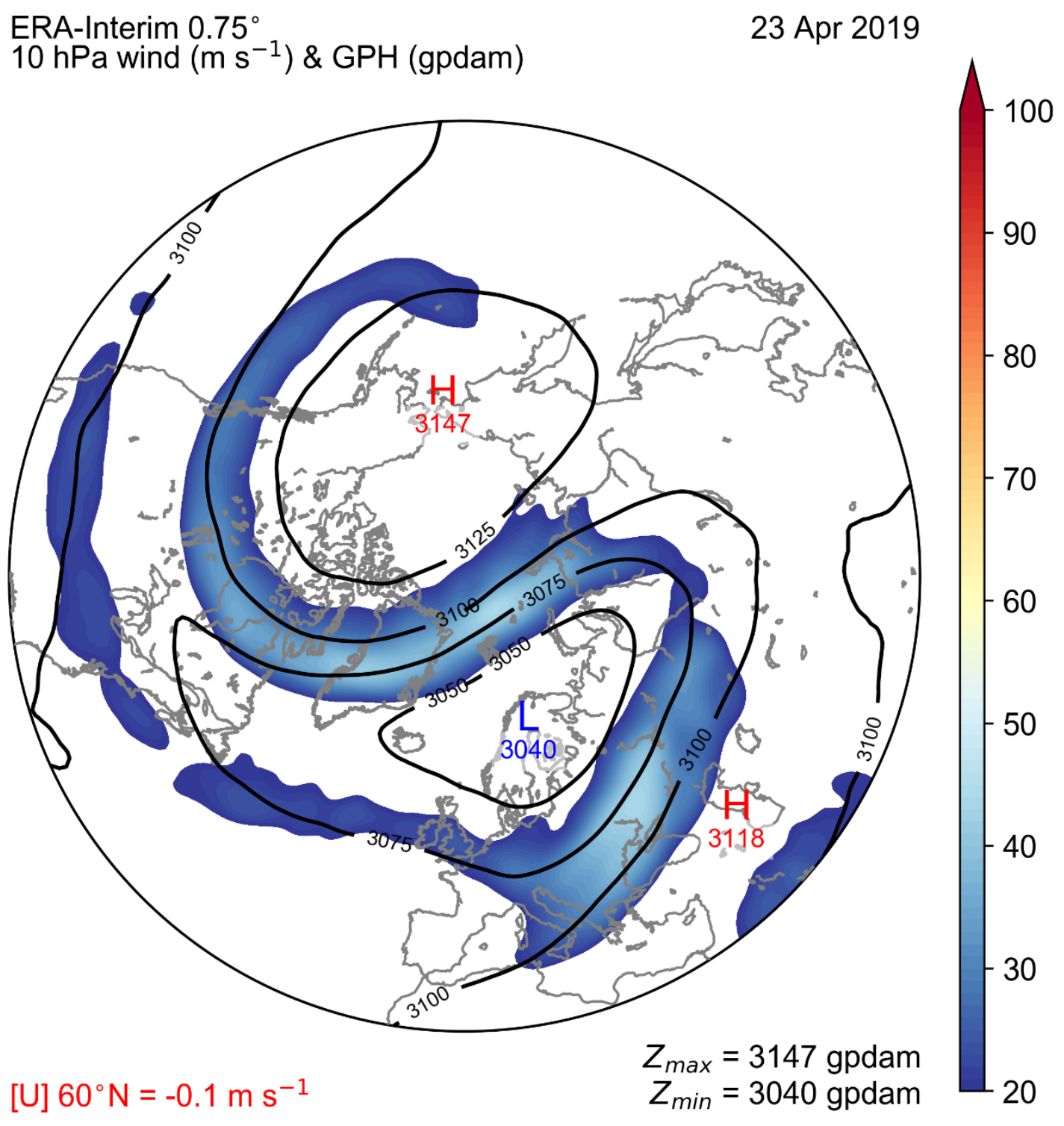

\section{[U] $60^{\circ} \mathrm{N}=-0.1 \mathrm{~m} \mathrm{~s}^{-1}$}

364 Figure 7: As in Figure 3 but for 23 April at the onset of the final warming. 


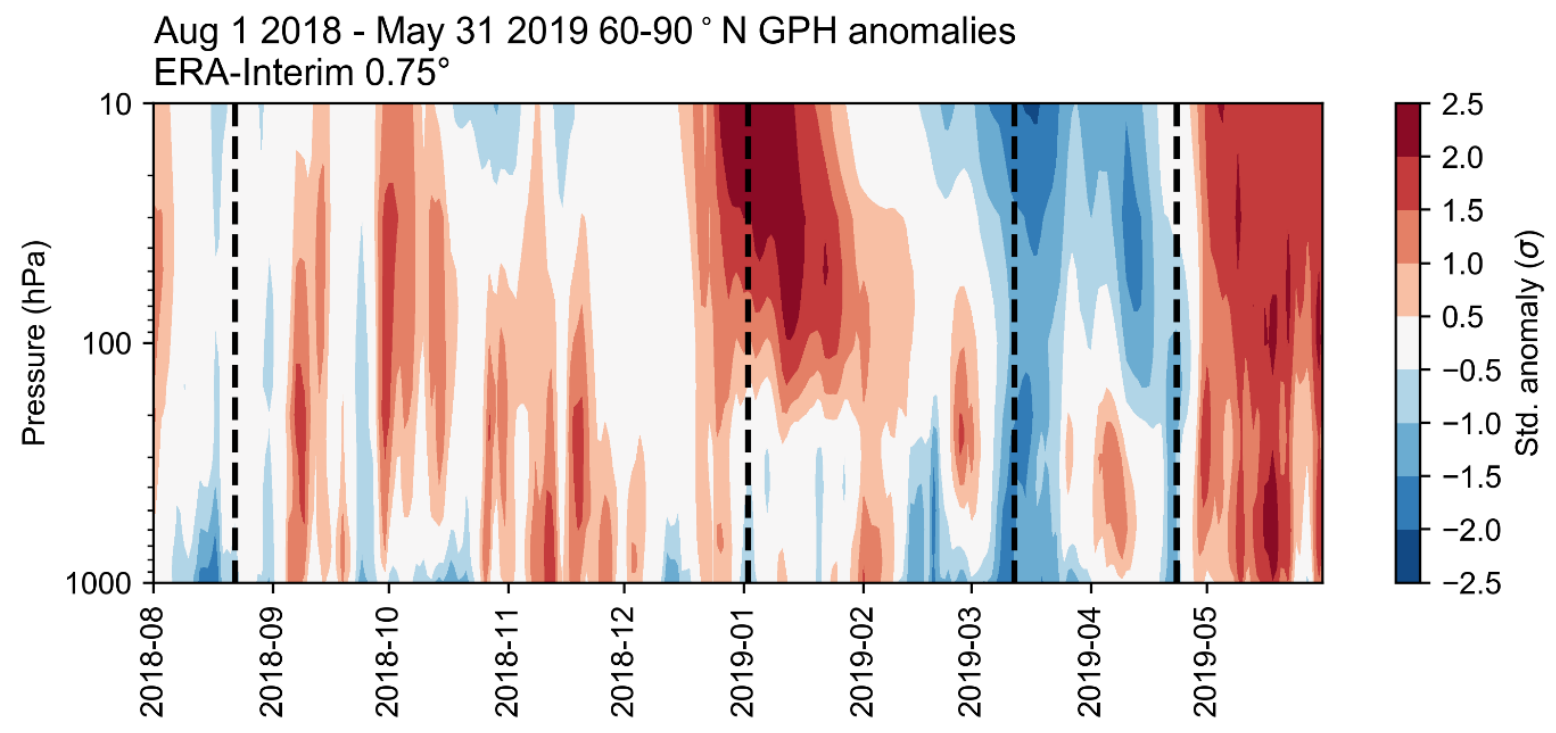

367 Figure 8: Timeseries of $60-90^{\circ} \mathrm{N}$ average geopotential height anomalies from 1 August 2018

368 through 31 May 2019 in ERA-Interim. Anomalies are standardized departures expressed with

369 respect to the daily mean and standard deviation from 1979-2019. Vertical dashed lines indicate

370 (from left-to-right) the vortex spin-up, the major SSW, the peak of the strong vortex event, and

371 the final warming.

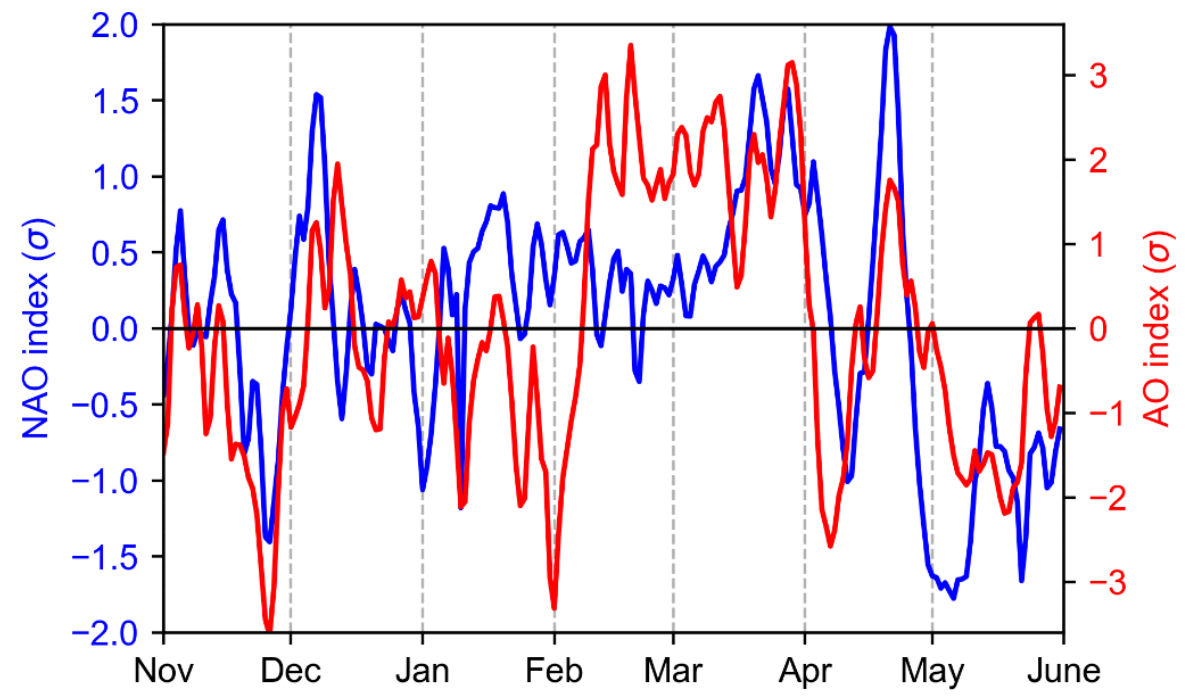

373 Figure 9: Timeseries of daily North Atlantic Oscillation (NAO, left-hand axis in blue) and

374 Arctic Oscillation (AO, right-hand axis in red) for 1 November 2018 to 31 May 2019. 